\title{
Why do we ignore our existing talent pool?
}

\author{
Richard Casey, MD, FRCS
}

Community Urologist, Oakville, ON, Canada

Cite as: Can Urol Assoc J 2020;14(5):E229. http://dx.doi.org/10.5489/cuai.6574

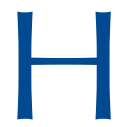
alton Healthcare Services is a large community hospital serving Halton/Peel district. We have two associated campuses, Milton district hospital and Georgetown. Georgetown is a small community on the cusp of exploding, population-wise, and will need a new facility in the next 8-10 years. It also needs a urologist and has been staffed by part-time surgeons for the last 50 years. It's time they have a full-time urologist on site, a position that was recently advertised.

Every applicant had considerable post-fellowship training. Uro-oncology, pediatric, andrology, and pelvic floor were represented in our interview list. While extra training is always good for your skill set, much of it will atrophy if your job is to look after a small community. Instead of complicated reconstructive cases, you will be overrun with large prostates, stones, and tight foreskins. The basic needs of our community should be our priority, but does it have to be at the expense of our newly acquired skills?

Of course not. There are options. I used to call my colleagues and say, "I hear you don't do radical prostatectomies (RPs). I like them; can I do some for you?" Within five years I was logging close to $100 \mathrm{RPs}$ a year. I had always enjoyed reconstructive work, so when the robots came and took away our prostates, I did the same with sphincters and slings/implants. I now implant about 80 slings/artificial urinary sphincters per year. I am a general community urologist first, with an interest that helps me avoid the tedium of community practice.

We shouldn't have to call around and ask for work, though. Just about every new graduate has subspecialty training. Often, the extra training is taken because there are no job opportunities or academic positions at their training sites. Rarely are graduates able to develop their secondary interests into a viable program unless they join an academic center. Volume is necessary and how many complex strictures are you going to see in a community of 80000 people?

New technology has allowed us to communicate efficiently and share our opinion with millions of others. I propose we use it to help Canadian patients gain access to the significant talent pool we have across Canada.
The Association of Community Urology Subspecialists is a pilot project to organize those non-academic surgeons who have special skills. I recently attempted to refer a complex stricture to our local tertiary center. The wait time was more than one year. This is unacceptable for patients. By identifying urologists (first in Ontario) who are skilled and interested in particularly complex clinical issues and providing that information to all community urologists, we hope to develop a referral network that supports our patients, as well as our community practitioners - for example, a urologist in Brampton who learned advanced laparoscopy and now does lap pyeloplasties, or someone in Whitby who did a fellowship in reconstructive urology and likes complex strictures.

By supporting fellow urologists through this network, we can help them enhance their skill set. We can also ask patients to participate in a feedback program that allows us to recalibrate referrals and improve our care. Community urologists shouldn't be doing 10 RPs a year if they know another surgeon who has a large volume and does good work. Implants, reversals, sphincters, robot prostatectomies - all are done better when the operator has a reasonable yearly volume. It doesn't matter where they are practicing.

Of course, this argument may not hold true with regards to uro-oncology, which often requires a multidisciplinary approach and chemotherapy or radiation. There are specialized centers throughout the country for these patients and they do a great job.

We would like to launch the aforementioned community urology subspecialists referral network initiative in Ontario and see if it works. I would appreciate feedback from any groups that have provided their communities with other solutions. There are several different methods we could use to effectively get patients to the urologist with the appropriate skill set. The first step is identifying the significant talent pool we have in Canada outside of academic centers.

Interested urologists can contact CUAJ via email at journal@cua.org. Let's start using the incredible talent pool we have in Canada. Let us know what your special skills are and we'll start a movement!

Correspondence: Dr. Richard Casey, Community Urologist, Oakville, ON, Canada; drrcasey@gmail.com 